\title{
Carbon budget of the vineyard - A new feature of sustainability
}

\author{
Andrea Pitacco and Franco Meggio \\ University of Padova - CIRVE, Viale dell’Università 16, 35020 Legnaro (PD), Italy
}

\begin{abstract}
Vineyards received scarce attention in relation to the continuous monitoring of carbon fluxes and the assessment of their overall budget, as a common believe is that agricultural crops cannot be net carbon sinks. Indeed, many technical inputs, massive periodical harvests, and the repeated disturbances of upper soil layers, all contribute to a substantial loss both of the old and newly-synthesized organic matter. Woody perennials, however, can behave differently: they grow a permanent structure, stand undisturbed in the same field for decades, originate abundant pruning debris, and are often grass-covered. We have been monitoring the Net Ecosystem Exchange (NEE) by eddy covariance and the carbon partitioning in a temperate vineyard in North Eastern Italy. Five complete yearly budgets confirm a steady and substantial sink capacity of the system, with a yearly NEE around $800-900 \mathrm{~g}_{C} \mathrm{~m}^{-2}$, grape harvest representing about $20-25 \%$ of it. Biometrical assessment of growth and partitioning show a good agreement with micrometeorological measurements and demonstrate a large input of organic matter into the soil. Even if it can be objected that this sink may be only temporary and the built-up can be substantially disrupted at the end of the vineyard life cycle, these results show that there is a concrete possibility of storing carbon in temperate-climate vineyards, possibly contributing to the global carbon budget. This sink capacity might be accounted in the official calculation of wine carbon footprint and represents a new, relevant feature of their sustainability.
\end{abstract}

\section{Introduction}

In the current climate change scenarios, both agriculture and forestry inherently may act as carbon sinks and thus play a strategic role in mitigating global warming. An urgent need exists to understand which agricultural land use and management have the greatest potential to mitigate greenhouse gas (GHG) emissions. In this context, reliable methods for quantifying and modelling also vineyard emissions and carbon sequestration potential are required. However, these data are relatively sparse, and more information is needed on management practices, to assess how they affect vineyard carbon (C) sequestration and GHG emissions, in order to calculate an accurate vineyard/cellar GHG footprint.

The OIV (International Organization of Vine and Wine) accepted the methodological structure of LCA and adopts a Carbon Footprint approach, i.e. a comprehensive measure of the amount of GHGs produced and consumed within a productive cycle, recently adapted also to the whole wine production chain for carbon footprint assessment [1]. However, assessing a carbon footprint for an individual vineyard is somewhat more complex, possibly including also mid-term sequestration of carbon in the vineyard. Unfortunately, agricultural crops received scarce attention in relation to the continuous monitoring of carbon fluxes and the assessment of their overall budget. Actually, a common believe is that agricultural fields cannot be net carbon sinks. Indeed, many technical inputs, massive periodical harvests of biomass, and the repeated disturbances of upper soil layers, they all contribute to a substantial loss both of the old and newly-synthesized organic matter.

Perennial tree crops, however, can behave differently: they grow a permanent woody structure, stand undisturbed in the same field for decades, originate a stable pruning debris, and are often grass-covered. For this reason and others, perennial crops, including vineyards, can be managed to reduce emissions and increase carbon storage, achieving a more positive balance [2-5].

The aim of the present work was to combine two largely deployed methods, eddy covariance and biometric measurements, to assess Net Ecosystem Production and allocation patterns in different plant organs in a commercial vineyard during five complete years. This first effort provides key information that helps improving the classical life cycle assessment method and could be included in the OIV protocol for carbon footprint of vineyards that is presently under development, underlining a possible positive role of vineyards on GHG budget through the quantitative assessment of carbon sequestration potential.

\section{Methods}

\subsection{Experimental site description}

In an extensive vineyard located in Negrisia di Ponte di Piave (North-Eastern Italy, $45^{\circ} 44^{\prime} 51^{\prime \prime} \mathrm{N}, 12^{\circ} 26^{\prime}$ $48^{\prime \prime}$ E, $9 \mathrm{~m}$ a.s.1.) special equipment for the continuous monitoring of $\mathrm{CO}_{2}$ fluxes has been deployed in July 2005 
and operated continuously. Climate is mediterranean, with a mean annual precipitation $833 \mathrm{~mm}$ and a mean annual temperature of $13.1^{\circ} \mathrm{C}$. The vineyard, mainly composed by Vitis vinifera L. cv. "Carmenère N." grafted on SO4 rootstock was planted in 1992 in north-south oriented rows spaced $2.50 \mathrm{~m}$ apart. Plant spacing on the rows was $1.30 \mathrm{~m}$, resulting in a density of 3,076 vines per hectare. Floor was grass covered, while a strip $1 \mathrm{~m}$ wide on the rows was chemically treated. Terrain is flat and plot size (25 ha) allows an adequate fetch $(\geq 200 \mathrm{~m})$ for most of wind directions.

Vineyard received standard management. Mechanical tipping and hedging, performed two times during the season. The spur-pruned cordon was at $1.70 \mathrm{~m}$ from ground. Maximum canopy height was kept at $2.70 \mathrm{~m}$, and maximum LAI, monitored both by direct and by indirect methods, peaked to 2.2 to 2.5 in July.

\subsection{Micrometeorological measurements}

The eddy covariance technique is the most straight- forward micrometeorological technique to measure turbulent fluxes [6]. Basically, it relies on the measurement of the instantaneous product of windspeed components and concentration of the scalar quantities of interest (heat, water vapour, carbon dioxide, etc.) in the boundary layer above the canopy. If terrain is flat and vegetation is extensive and homogeneous, horizontal components of motion may be neglected and analysis can focus on the vertical component only.

The instantaneous flux $f$ of a generic scalar quantity thus reduces to:

$$
f=w \chi
$$

where $w$ is the vertical component of windspeed and $\chi$ is the mixing ratio of the scalar. The stochastic nature of atmospheric motion is conveniently analyzed by decomposing the instantaneous values in a slowly-varying average component (indicated by an overbar) and in a fluctuation (indicated by a prime):

$$
f=\left(\bar{w}+w^{\prime}\right)\left(\bar{\chi}+\chi^{\prime}\right)
$$

thus originating four products:

$$
f=\overline{w \chi}+\bar{w} \chi^{\prime}+w^{\prime} \bar{\chi}+w^{\prime} \chi^{\prime} .
$$

As we are more interested in time averages rather than in the individual transport events, the mean flux $F$ is given by:

$$
\begin{gathered}
F=\bar{f} \\
F=\overline{\overline{w \chi}}+\overline{\bar{w} \chi^{\prime}}+\overline{w^{\prime} \bar{\chi}}+\overline{w^{\prime} \chi^{\prime}}
\end{gathered}
$$

which, considering that the average of fluctuations is zero and that average vertical speed is also close to zero on flat terrain, reduces to the covariance between vertical windspeed and scalar concentration:

$$
F=\overline{w^{\prime} \chi^{\prime}} \text {. }
$$

Both $w$ and $\chi$ must be measured at a frequency high enough to catch most of turbulent frequencies.

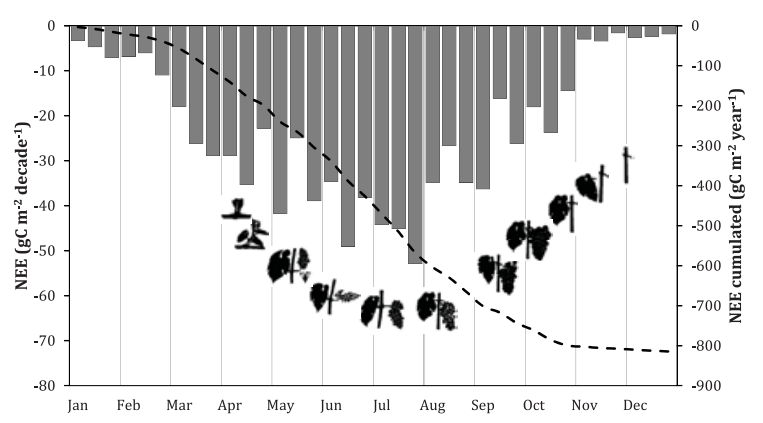

Figure 1. Yearly course of NEE on a decadal basis and cumulated throughout the season.

\subsection{Net Ecosystem Productivity (NEP) determi-nation and partitioning}

Net ecosystem carbon exchange (NEE) fluxes were monitored by eddy covariance from July 2005 and operated continuously. The eddy covariance equipment is based on a 3-dimensional ultrasonic anemometer (Metek USA-1) and an open-path IR gas analyzer (LiCor LI7500 ), both logged at $20 \mathrm{~Hz}$ by a low-power industrial PC. Ancillary measurements of net radiation (Kipp \& Zonen CNR-1) and basic meteorological parameters (air temperature and humidity, barometric pressure, rainfall, etc.) are measured every second and averaged every 30 minutes by a CR23X Campbell datalogger. In the present paper, data collected for the year 2009 will be presented. Eddy Covariance data were processed according to the standard EUROFLUX methodology [7]. Data quality check has been performed according to [8] and gap-filling followed [9].

Fluxes measurements were coupled with biometric surveys to directly assess the net primary production (NEP) and its partitioning pattern within the vineyard. Extensive biometrical sampling of leaves, shoots, trunks and roots has been carried out to provide independent measurements of growth dynamics of vines and biomass partitioning.

Total biomass determination, comprising perennial above ground and below ground biomass, was made at two stages of vines development, in 2007 and 2010. Aboveground net primary productivity (ANPP) was estimated on the basis of the annual increment of dry biomass of aboveground organs. Destructive samplings conducted during the experimental period enabled a further partitioning to be assessed between leaves and wood of primary and lateral shoots. Below-ground net primary productivity (BNPP) was determined by estimating the root growth assuming a constant aboveground/belowground biomass ratio between the two sampling dates $(2007,2010)$.

\section{Results}

Since the establishment of the station, the vineyard proved to be a strong carbon sink. Figure 3 showed a rapid increase of NEE already before budbreak, due to the increased activity of the grass cover as soon as temperature became milder. The quick development of vine canopy further increased carbon absorption up to a maximum daily NEE of about $6 \mathrm{~g}_{C} \mathrm{~m}^{-2}$, occurred around veraison. Leaf 


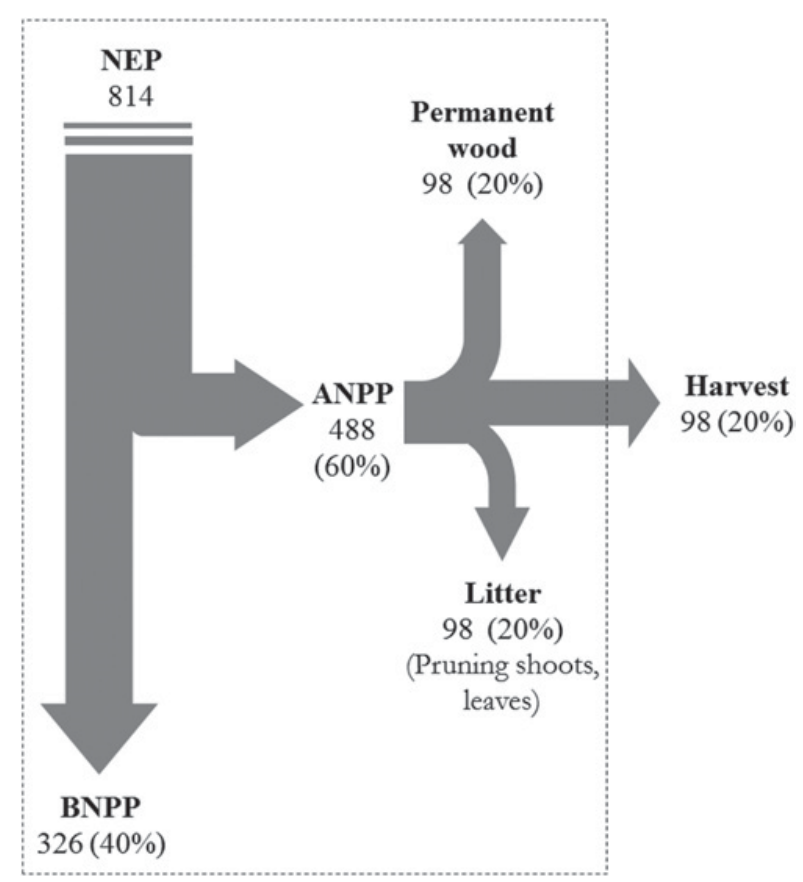

Figure 2. Sankey plot of the carbon cycle of the vineyard for the season 2009. Data are in $\mathrm{g}$ of $\mathrm{C} \mathrm{m}^{-2} \mathrm{yr}^{-1}$ for each component of the $\mathrm{C}$ cycle: $\mathrm{ANPP}=$ Above ground Net Primary Productivity, $\mathrm{BNPP}=$ Below-ground Net Primary Productivity, NEP $=$ net ecosystem productivity; Harvest $=$ grapes production exported from the ecosystem.

senescence and fall brought a steep decay of NEE by the end of October. However, the system never showed a net release of carbon, because of the residual activity of the grass cover even during wintertime.

In the monitored year, the average measured net ecosystem productivity $(\mathrm{NEP}=-\mathrm{NEE})$ was around $814 \mathrm{~g}_{C} \mathrm{~m}^{-2} \mathrm{y}^{-1}$ which matched very well the biometrical measurements. Yield represented roughly $20 \%$ of NEE and therefore Negrisia vineyard behaved as a carbon sink even after harvest. Obviously, this behaviour very much reflects both the adequate water availability (the vineyard never experienced significant stress, because of the generally high water table of the area) and the mild temperature (seldom below $0{ }^{\circ} \mathrm{C}$ ).

Total ANPP and BNPP represented the $60 \%$ of NEP $\left(488 \quad \mathrm{~g}_{C} \mathrm{~m}^{-2} \mathrm{y}^{-1}\right)$ and the $40 \%$ of NEP $\left(326 \mathrm{~g}_{C} \mathrm{~m}^{-2} \mathrm{y}^{-1}\right)$ respectively. The total ANPP was further equally partitioned among perennial wood, litter and grapes harvest representing both around the $20 \%$ of NEP $\left(98 \mathrm{~g}_{C} \mathrm{~m}^{-2} \mathrm{y}^{-1}\right)$.

\section{Conclusions}

Even if it can be objected that this sink may be only temporary and the built-up can be substantially disrupted at the end of the grapevine life cycle, these results show that there is a concrete possibility of storing carbon in vineyards soils. Biometrical assessment of growth and partitioning show a good agreement with micrometeorological measurements and demonstrate a large input of organic matter into the soil. Vineyards seem to be good candidates but proper practices must be defined to preserve this storage at best and extend point measurements to regional estimates through defensible and reliable methodologies.

\section{References}

[1] C. Pattara, A. Raggi, A. Cichelli, Environ. Manage. 49, 1247 (2012)

[2] Pitacco A, Meggio F, Giulivo C. 2007. In: Mainar M.A. (ed.) Proceedings of the Congress on Climate and Viticulture, 10-14 July 2007, Zaragoza, Spain, 7, 36 (2007)

[3] Nardino, M., Pernice, F., Rossi, F., Georgiadis, O., Facini, A., Motisi, A., Drago, A., Photosynthetica. 5, 63 (2013)

[4] Zanotelli, D., Montagnani, L., Manca, G., and Tagliavini, M., Biogeosciences. 10, 3089 (2013)

[5] Gianelle D., Gristina L., Pitacco A., Spano D., La Mantia T., Marras S., Meggio F., Novara A., Sirca C., Sottocornola M., In: R. Valentini, F. Miglietta (eds.), The Greenhouse Gas Balance of Italy. Springer.

[6] Baldocchi, D.D., Hincks B.B., Meyers, T.P., Ecology 69, 1331 (1988)

[7] Aubinet M., Grelle A., Ibrom A., Rannik U., Moncrieff J., Foken T., Kowalski A.S., Martin P.H., Berbigier P., Bernhofer Ch., Clement R., Elbers J., Granier A., Grunwald T., Morgenstern K., Pilegaard K., Rebmann C., Snijders W., Valentini R., Vesala T., Adv. Ecol. Res. 30, 113 (2000)

[8] Foken, T., Wichura, B., Agric. For. Meteor. 78, 83 (1996)

[9] Desai, A.R., Bolstad, P., Cook, B.D., Davis, K.J., Carey, E.V., Agric. For. Meteorol. 128, 33 (2005) 